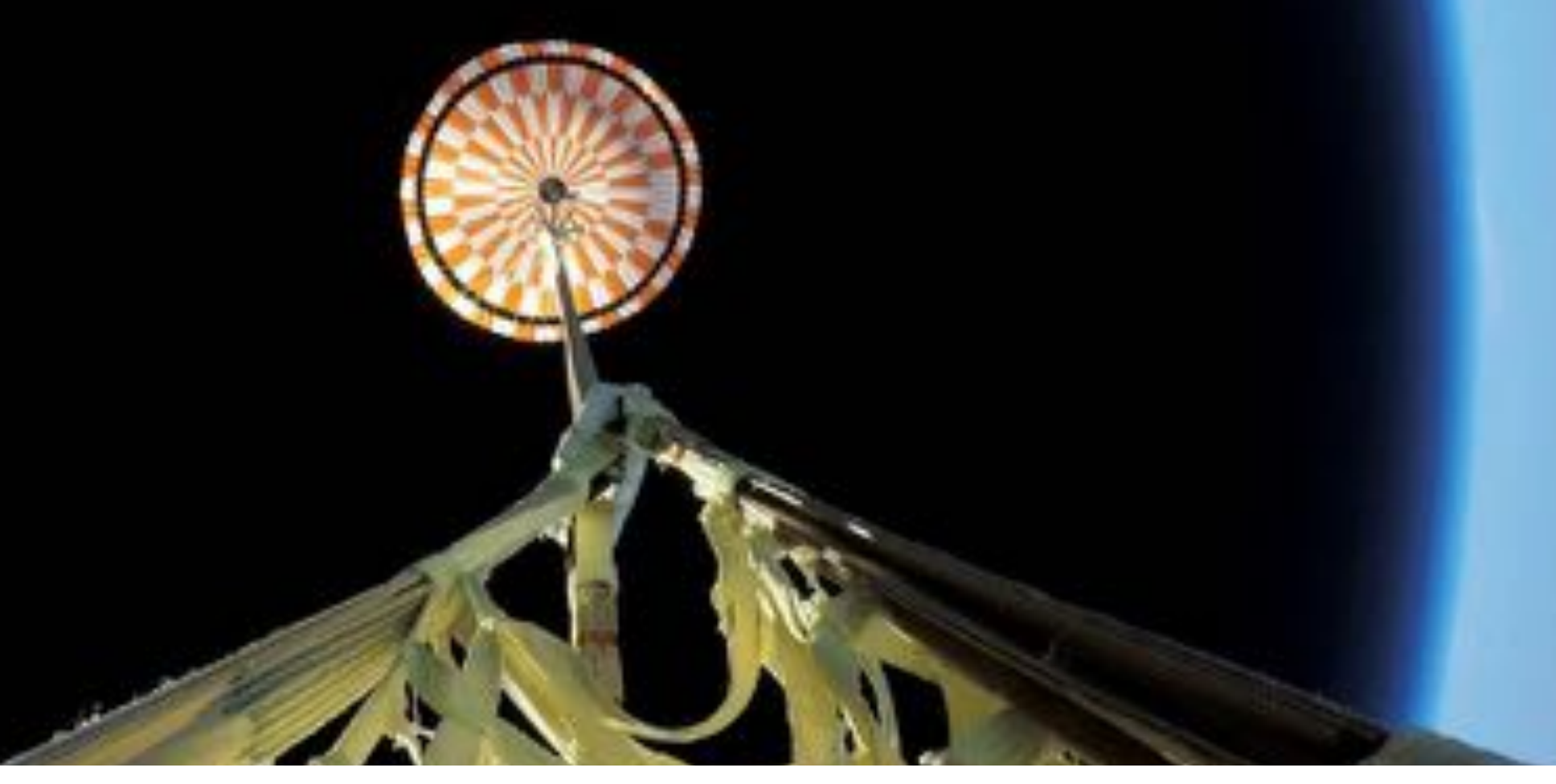

\title{
Modeling and Flight Performance of Supersonic Disk-Gap-Band Parachutes in Slender Body Wakes
}

Suman Muppidi

AMA Inc., NASA Ames Research Center

Clara O'Farrell, Christopher Tanner, lan Clark Jet Propulsion Laboratory, California Institute of Technology

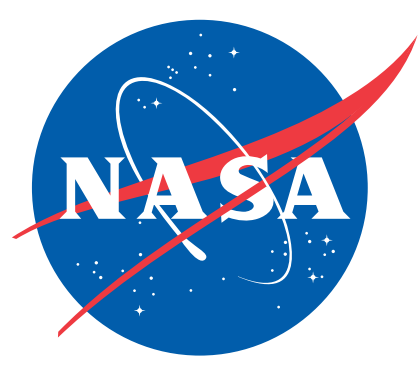




\section{Introduction}

- Disk-Gap-Band (DGB) parachutes have been used on all US Mars missions.

- All of the parachutes have been variants of the Viking DGB parachute.

- Wind Tunnel Testing

- Low-altitude drop testing

- High-altitude supersonic Testing

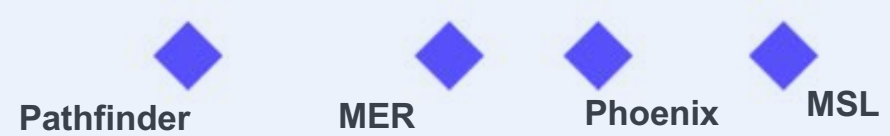

MSL Mars2020

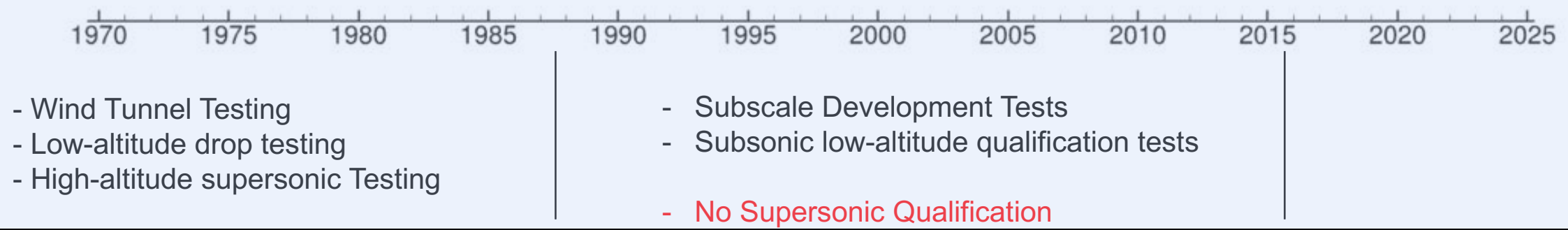

- Since Viking era,

- Parachute materials have changed (Dacron $\rightarrow$ Kevlar, Nylon)

- Analysis methods have become smarter

- Parachute size and load have increased

- Design Margins have decreased

- Relationship between flight performance and subsonic testing is not clear

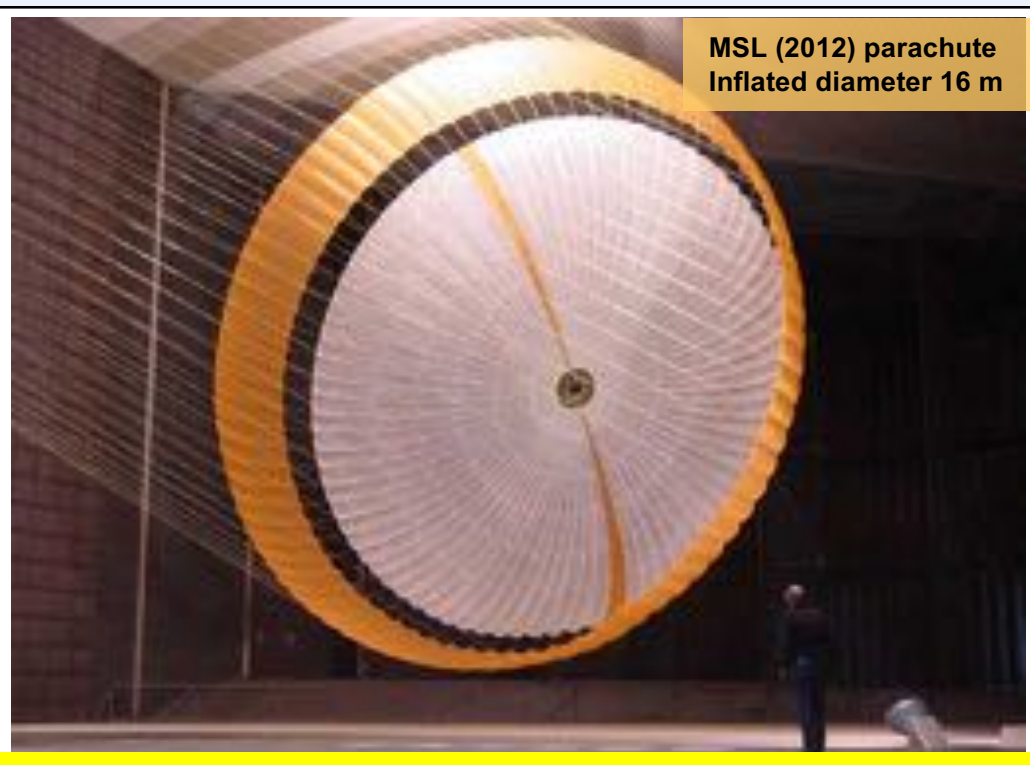

The Advanced Supersonic Parachute Inflation Research and Experiments (ASPIRE) project is tasked with deployment and testing of full-scale Disk-Gap-Band parachutes at Mars relevant conditions 


\section{ASPIRE}

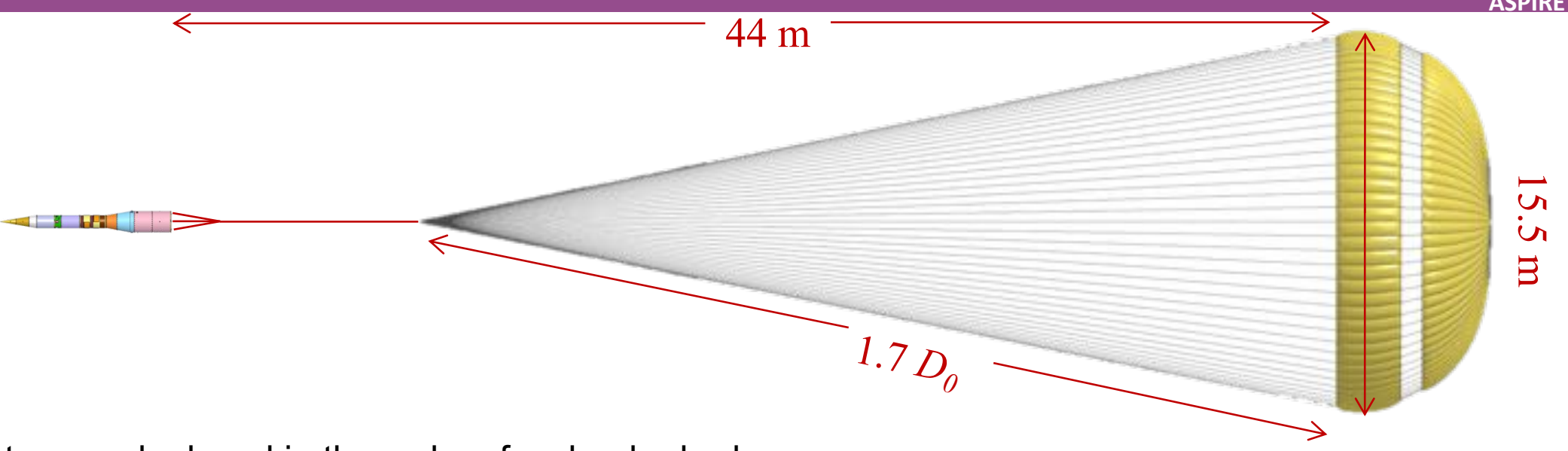

- Parachutes are deployed in the wake of a slender body (at high altitudes over Earth).

- Two different parachutes are being tested.

- The qualified parachute will be used at Mars behind a blunt body (Mars2020).

\begin{tabular}{|l|l|l|}
\hline Test & Parachute & Target Parachute load \\
\hline SR01 (Oct 2017) & MSL built-to-print & $35000 \mathrm{lbf}(\mathrm{MSL})$ \\
\hline SR02 (Mar 2018) & Strengthened & $47000 \mathrm{lbf}(99 \%$ high) \\
\hline SR03 (Jul 2018) & Strengthened & $70000 \mathrm{lbf}(2 \times \mathrm{MSL})$ \\
\hline
\end{tabular}

ASPIRE Disk-Gap-Band (DGB) Parachute

- Reference Diameter $\left(D_{0}\right) \quad 21.5 \mathrm{~m}$

- Inflated Diameter $\quad 15.5 \mathrm{~m}$

Dimensions similar to MSL parachute
ASPIRE payload

Max diameter

Max length

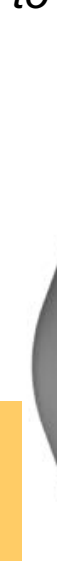




\section{ASPIRE Flight Test}
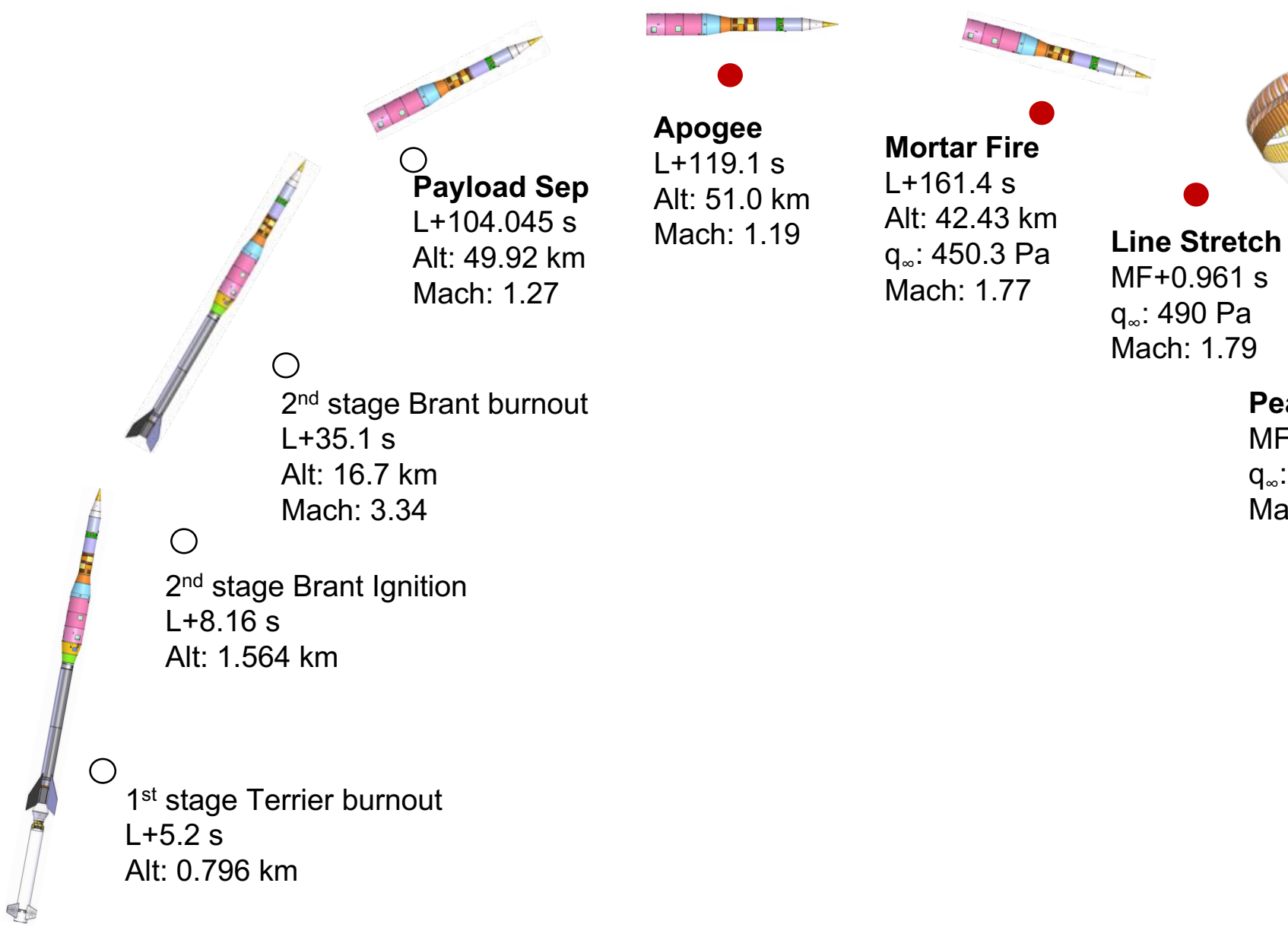

\section{Peak Load}

$\mathrm{MF}+1.47 \mathrm{~s}$

$\mathrm{q}_{\infty}: 500.0 \mathrm{~Pa}$

Mach: 1.79

\section{Launch Site} (WFF, VA) 


\section{ASPIRE Flight Test}
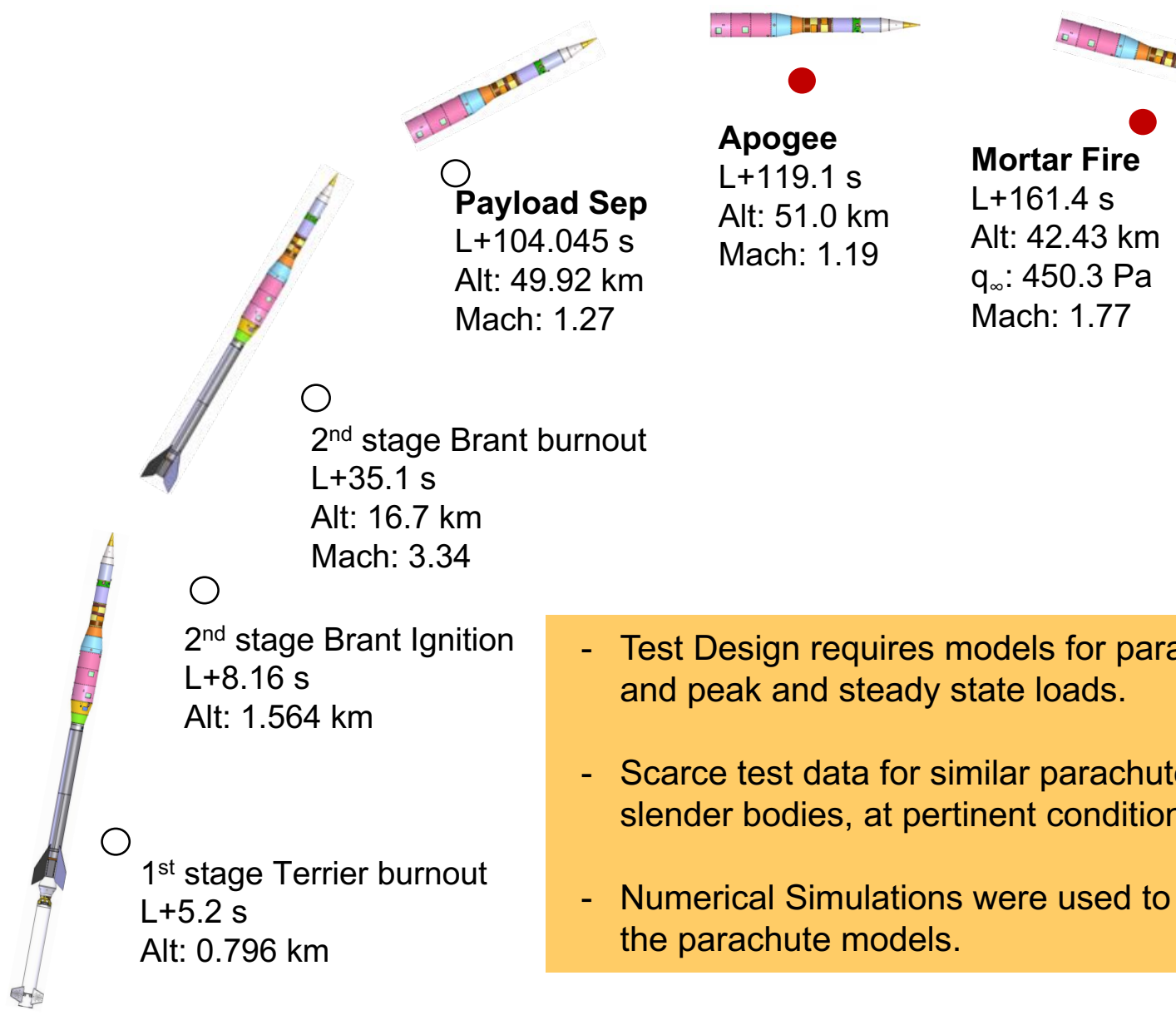

$\rightarrow \rightarrow$

Mortar Fire

$\mathrm{L}+161.4 \mathrm{~s}$

Alt: $42.43 \mathrm{~km}$

Mach: 1.77

Line Stretch

$\mathrm{MF}+0.961 \mathrm{~s}$

$\mathrm{q}_{\infty}: 490 \mathrm{~Pa}$

Mach: 1.79

\section{Peak Load \\ $\mathrm{MF}+1.47 \mathrm{~s}$ \\ $\mathrm{q}_{\infty}: 500.0 \mathrm{~Pa}$ \\ Mach: 1.79}

- Test Design requires models for parachute inflation, and peak and steady state loads.

- Scarce test data for similar parachutes behind slender bodies, at pertinent conditions.

- Numerical Simulations were used to help generate the parachute models.
Nosecone Jettison

Alt: $3 \mathrm{~km}$

Splashdown

$\mathrm{L}+34 \mathrm{~min}$

\section{Atlantic Ocean}

\section{Launch Site} (WFF, VA) 


\section{Mean Flow Field}

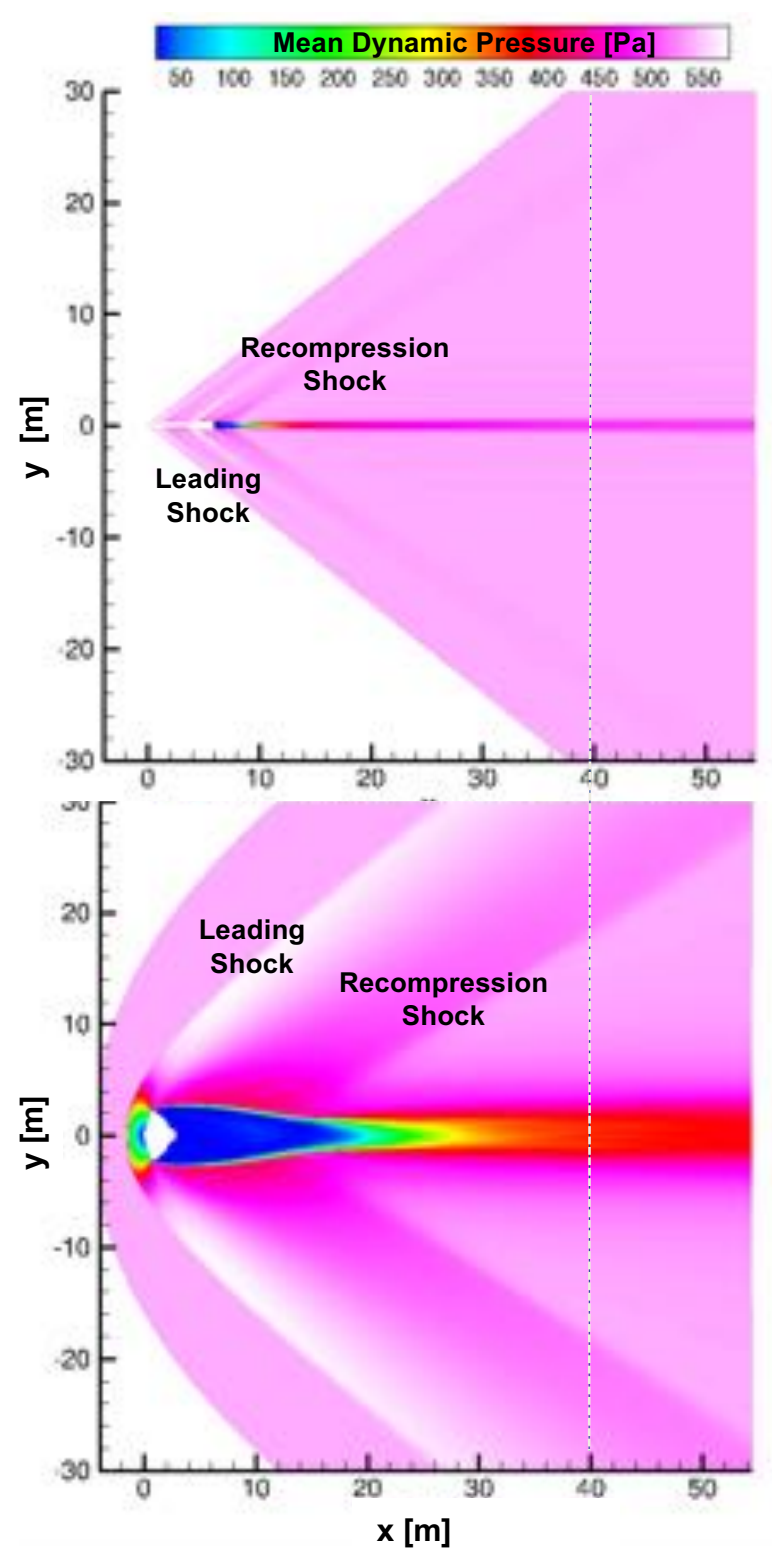

- In general, wake characteristics scale with the diameter; $D_{\mathrm{MSL}} / D_{\mathrm{ASPIRE}} \sim 6$

- The wake behind the slender body closes much earlier; is thinner.

- Dynamic pressure recovery $\left(\mathrm{q}_{\min }\right)$ much faster behind the slender body, compared to the blunt body.

- Deficit (velocity, dynamic pressure) is larger, behind the blunt body.

- Parachute drag is directly dependent on dynamic pressure. We should expect lower drag behind a blunt body.

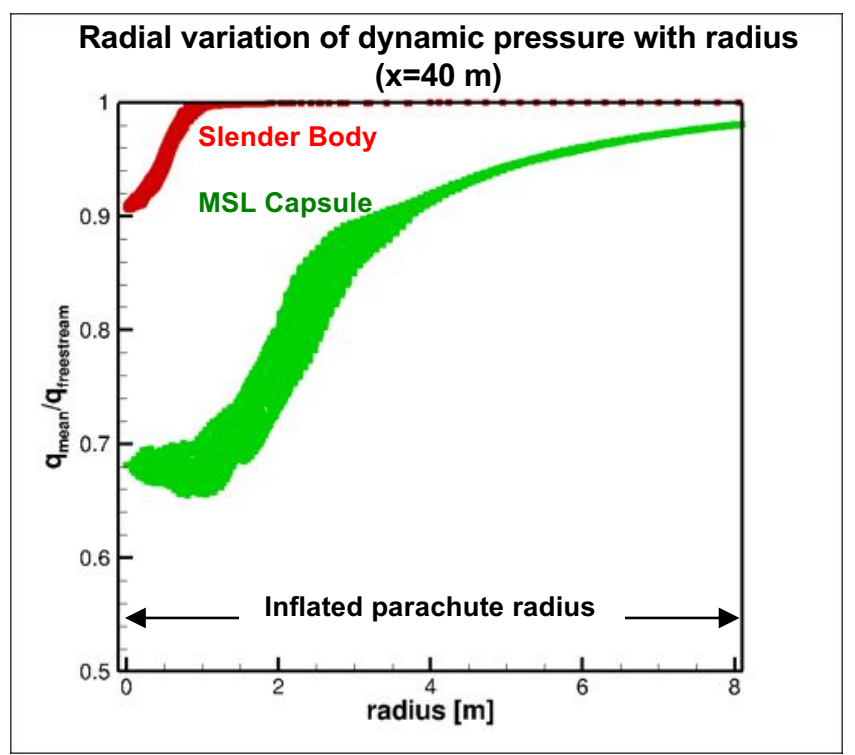




\section{Temporal Unsteadiness}

ASPIRE
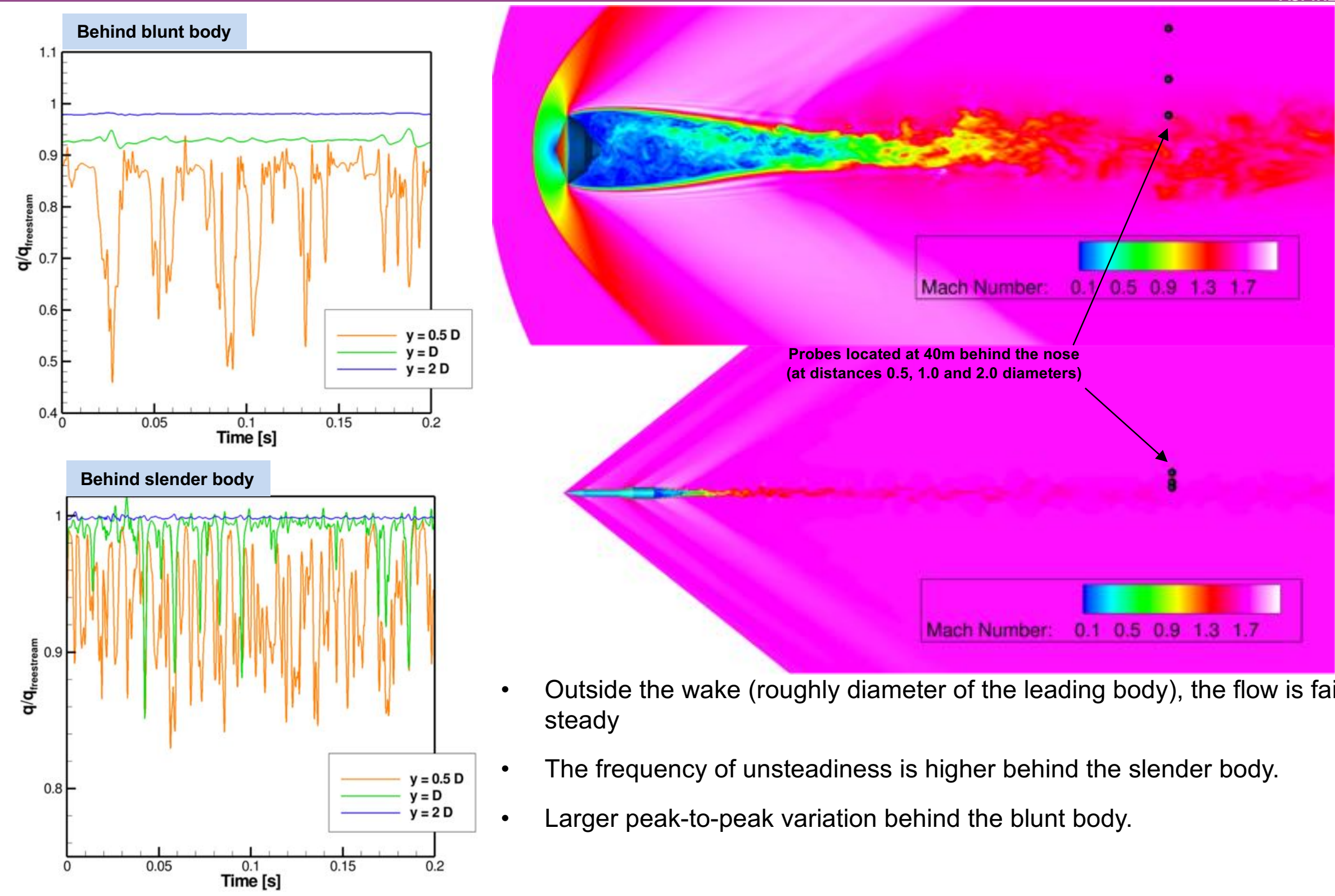

- Outside the wake (roughly diameter of the leading body), the flow is fairly steady

- The frequency of unsteadiness is higher behind the slender body.

- Larger peak-to-peak variation behind the blunt body. 


\section{Implications to Flight Test Design}
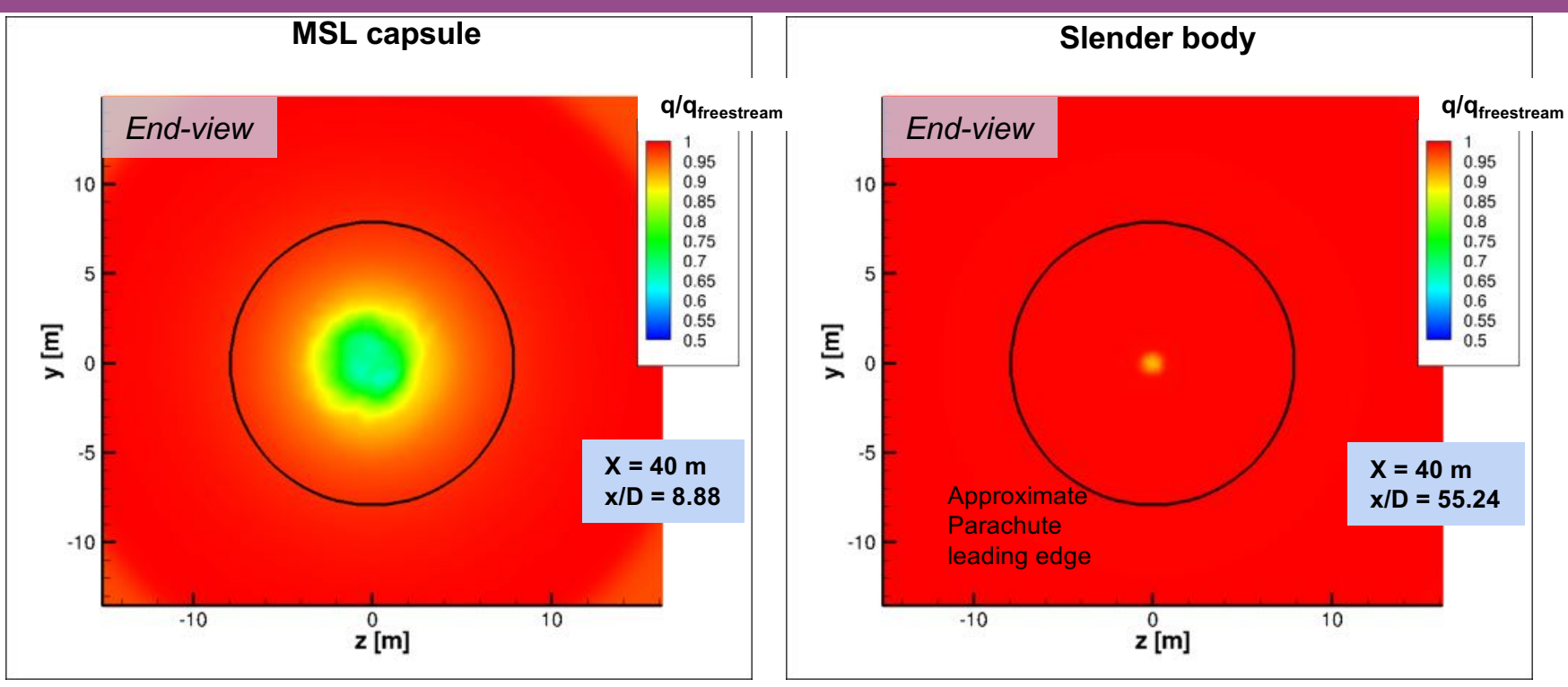

- Parachute pack behind a blunt body could see a dynamic pressure $50-90 \%$ of freestream value; this likely range is smaller behind a slender body: $90-100 \%$ of freestream dynamic pressure.

- Parachute inflation behind a slender body could be more stressing.

- Peak parachute load (M2020 model) is estimated as a function of the freestream dynamic pressure as

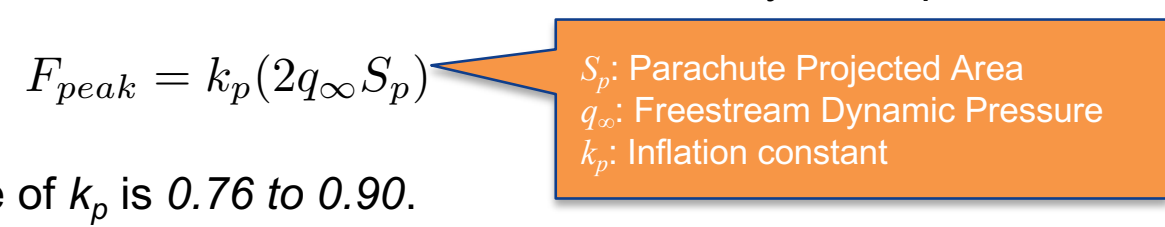

- For MSL/M2020 parachute, estimated range of $k_{p}$ is 0.76 to 0.90 .

- ASPIRE payload has a smaller wake deficit $\rightarrow$ adjusted $k_{p}$ range: 0.76 to 0.98 .

(for the same dynamic pressure and parachute, higher inflation load behind the ASPIRE payload) 


\section{Simplified Parachute Simulations}
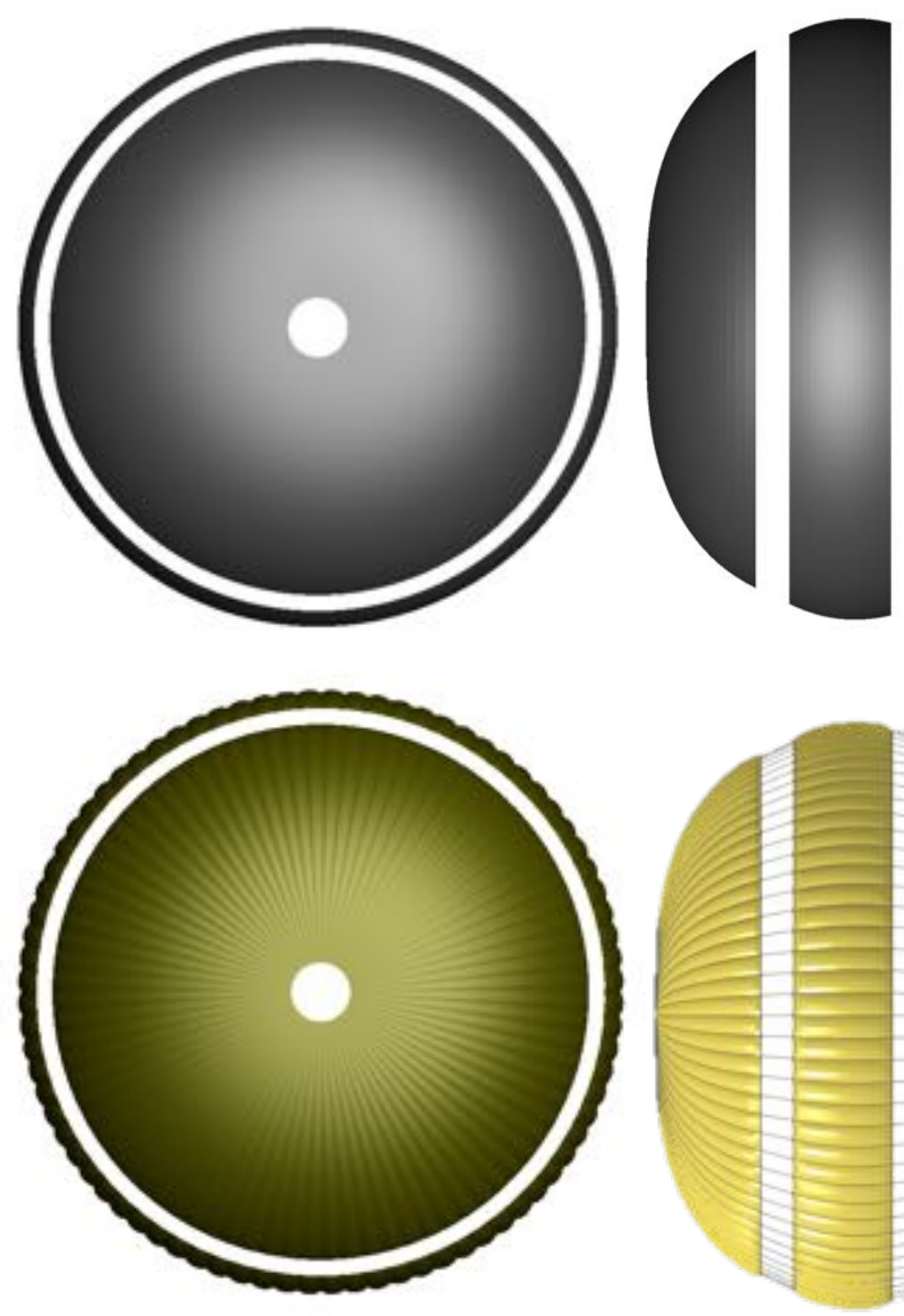

- Parachute simplified as a surface of revolution.

- Treated as rigid, impermeable, $1 \mathrm{~mm}$ shell.

- Risers and lines are not modeled.

- Geometry maintains the disk-gap-band configuration.

- Parachute is placed $45 \mathrm{~m}$ behind the leading body.

- Same freestream as the wake simulations

- Mach number 1.75; Dynamic Pressure $538 \mathrm{~Pa}$

Q. What is the effect of the leading body on the steady-state parachute drag? 


\section{Effect of Leading Body}

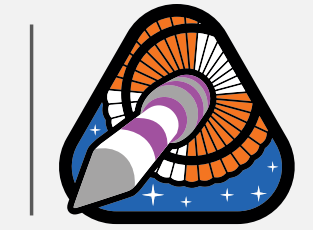

ASPIRE

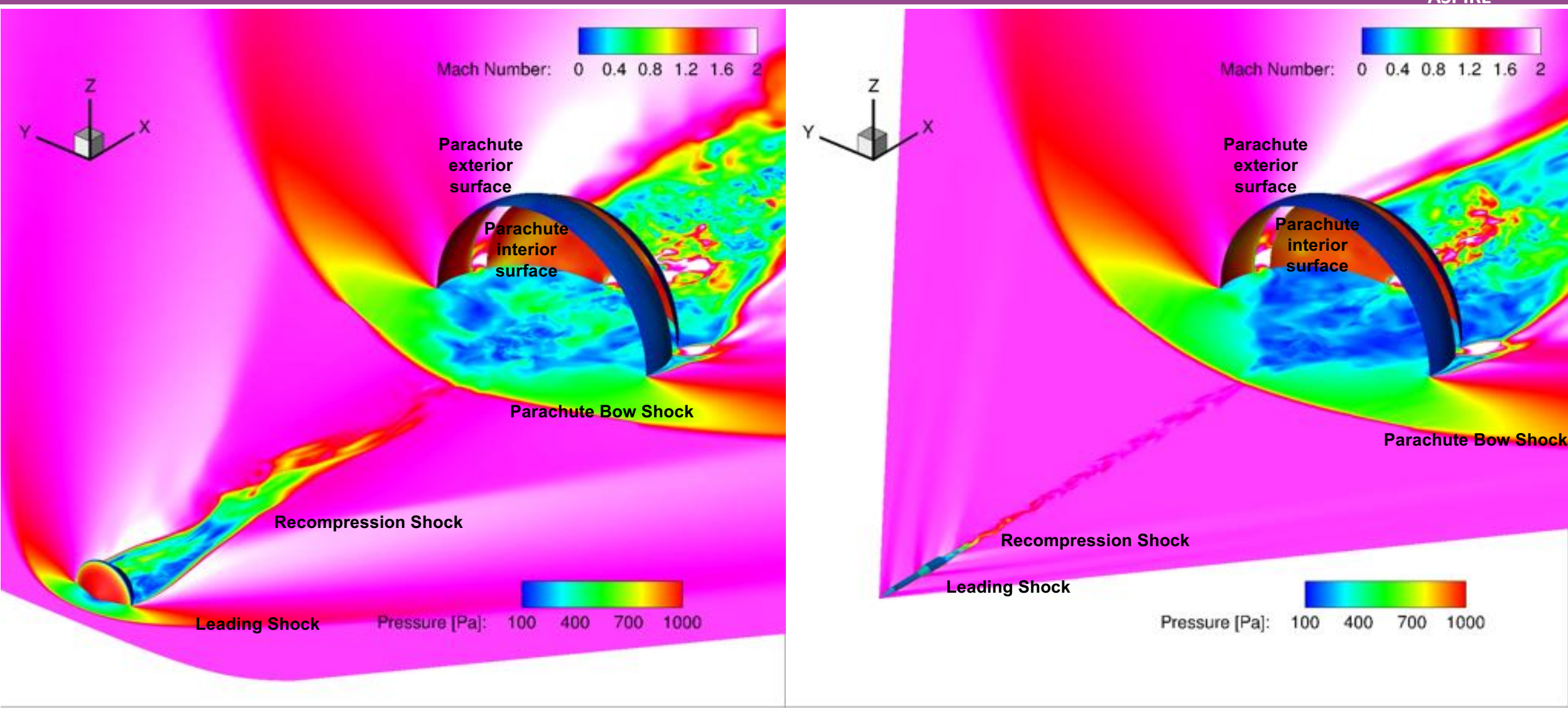

- Unsteady flow starting at the wake of the leading body; flow acceleration through the vent and the gap.

- Interaction between the wake and the parachute shock is more apparent behind the blunt body.

- $\quad$ Behind the slender body, the parachute bow shock barely registers the (narrow) wake. 


\section{Development of Pre-Flight Drag Model}

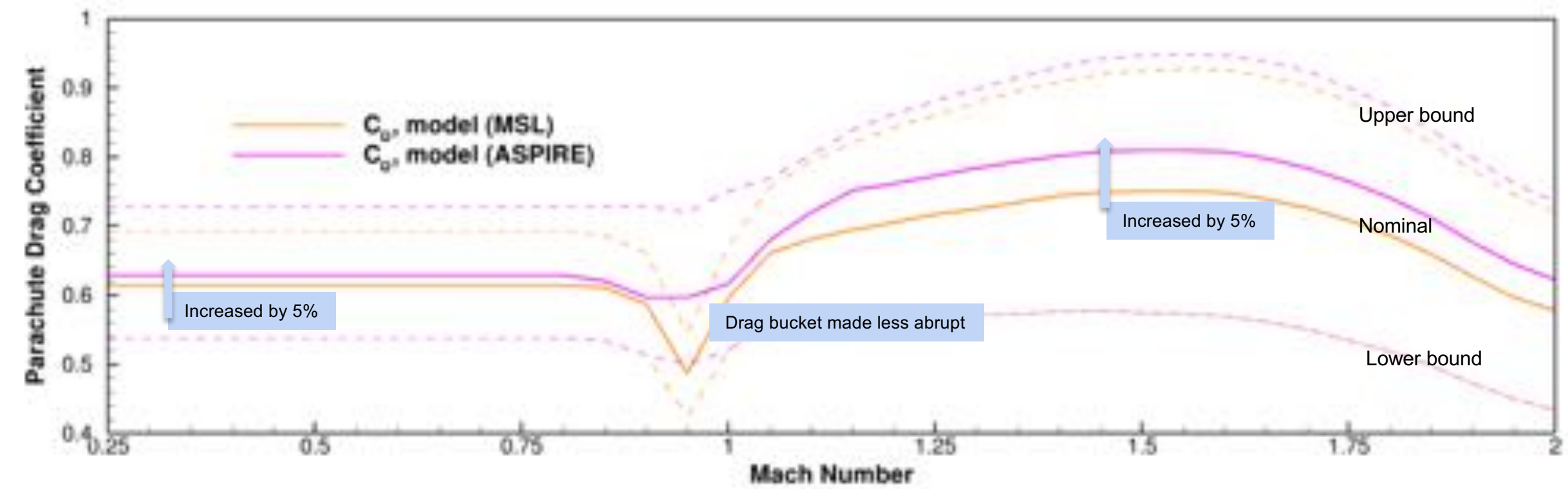

- MSL parachute drag model was modified to yield the ASPIRE parachute drag model.

- The modifications were informed by flight and wind tunnel tests, and numerical simulations

Subsonic: Increased nominal drag performance and the high margin; retained the low margin

Supersonic: Increased nominal drag performance and the high margin; retained the low margin

Transonic: reduced the steep reduction at near-sonic conditions; blended the subsonic and supersonic drag curves

- The ASPIRE drag model (and the bounds) was used in the flight mechanics simulations, and to help design the flight tests. 


\section{Air vs $\mathrm{CO} 2$}

\section{Q. What is the effect of the freestream gas on the parachute drag?}

ASPIRE

\section{Freestream Details}

\begin{tabular}{|c|c|}
\hline Atmosphere & Density/Al \\
\hline Air, perfect gas & $0.00346(\mathrm{~K}$ \\
\hline CO2, perfect gas & 0.00605 (K \\
\hline Simulations in $\mathrm{CO}_{2}$ \\
\hline
\end{tabular}

- $\quad$ Simulations of parachute behind the MSL capsule in air and $\mathrm{CO}_{2}$ at the same Mach number and freestream dynamic pressure.

- $\quad$ The two fluids have different values for ratio of Specific Heats ( $\mathrm{\gamma})$ :

- Air: 1.4

$-\mathrm{CO}_{2}: 1.3$

- $\quad \gamma$ affects shock standoff distance and conditions across the shock, which in turn affect pressure on the parachute, and the parachute performance.

- $\quad$ Simulations at M 1.75 show very similar performance in both gases (unsteadiness, and parachute drag); mean parachute drag varies by only $2 \%$.

- $\quad \gamma$-effects not very significant at this Mach number (e.g. post-shock total pressure ratio is within $2.5 \%$ ).

Simulations indicate that at this Mach number, a high-altitude Earth test is a good proxy for a Mars flight 


\section{SR01 Flight Test}

\section{The First Few seconds}

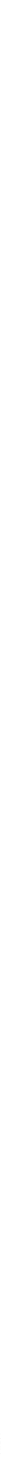




\section{SR01 Flight Test}

\section{High Above the Earth}

ASPIRE

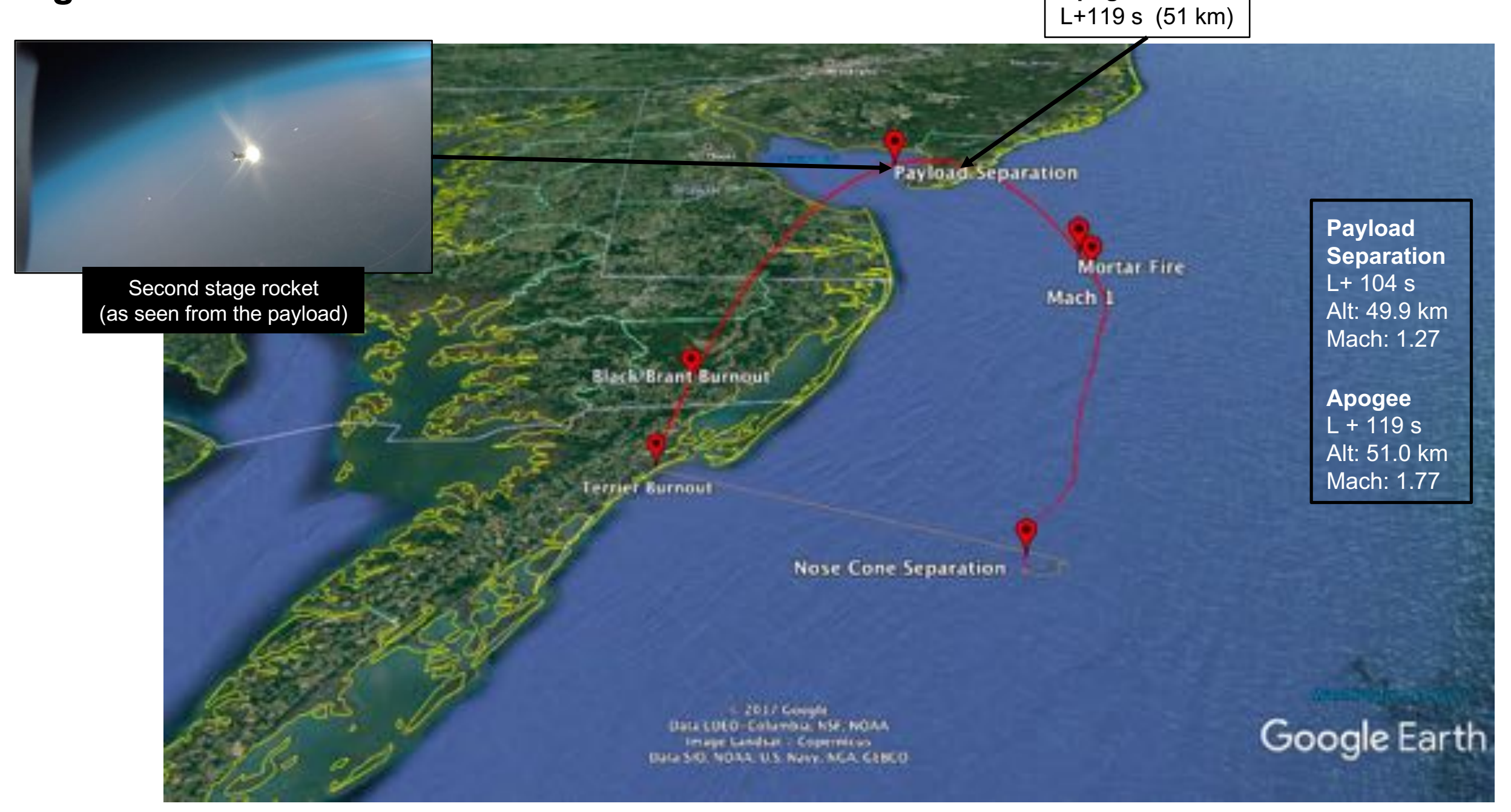




\section{SR01 Flight Test}

\section{Parachute Deployment and Inflation}

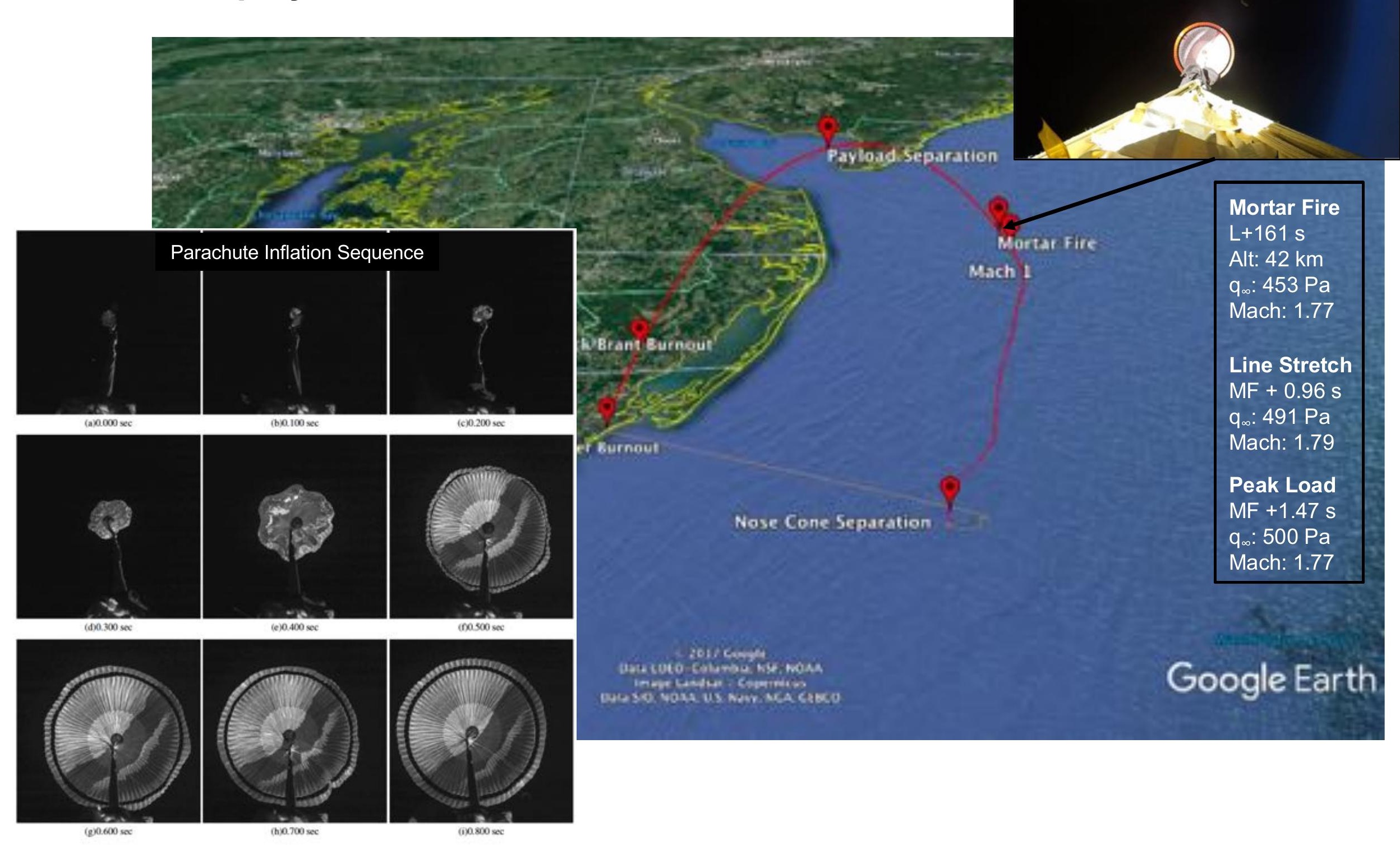




\section{SR01 Flight Test}

\section{Splashdown and Recovery}

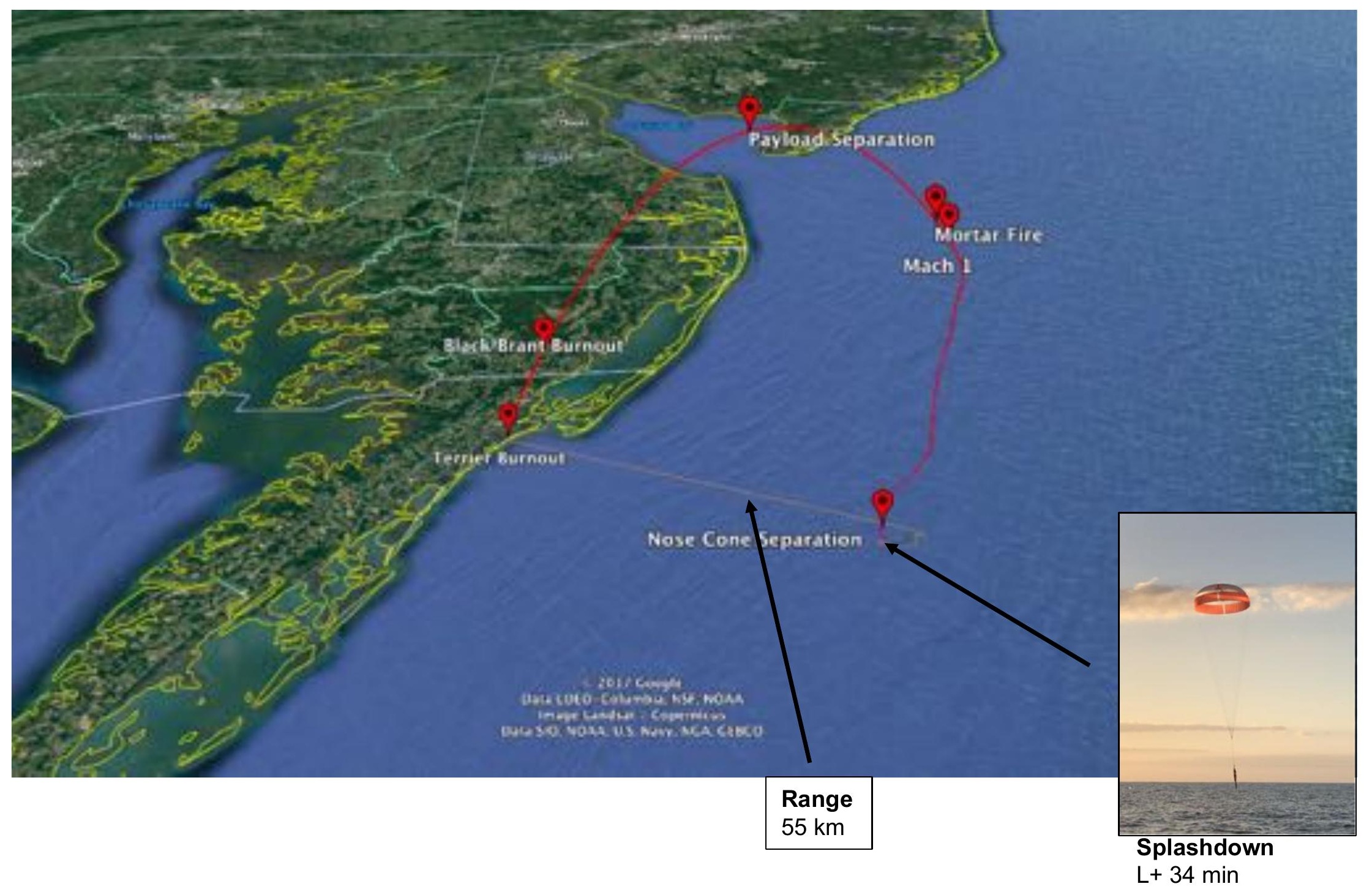




\section{SR01 Flight Test Summary}

ASPIRE

\begin{tabular}{|l|c|c|c|c|}
\hline Event & Time from launch & Mach number & $\begin{array}{l}\text { Dynamic pressure } \\
(\mathrm{sec})\end{array}$ & $\begin{array}{l}\text { Wind-relative } \\
\text { velocity }(\mathrm{m} / \mathrm{s})\end{array}$ \\
\hline Payload Separation & 104.03 & $1.27(1.2)$ & $87.15(86.1)$ & 407.8 \\
\hline Apogee & 119.04 & 1.19 & 65.74 & $49.92(49.9)$ \\
\hline Mortar Fire & 161.41 & $1.77(1.74)$ & $452.53(438.4)$ & $51(50.9)$ \\
\hline Peak Load & 162.88 & $1.77(1.72)$ & $494.88(473.0)$ & 560.29 \\
\hline
\end{tabular}

- $\quad$ Exceeded dynamic pressure at peak load by $4.6 \%$ (All the flight events were very close to pre-flight predictions)

Load pins in the parachute assembly measure the tension (Parachute force $=$ tension + payload mass $\mathrm{x}$ acceleration)

Peak Aerodynamic Load $=32.4 \mathrm{k} \mathrm{lbf}=144.07 \mathrm{kN}$ (Pre-flight prediction $35 \mathrm{k} \mathrm{Ibf}$ )

- Inflation load indicator $F_{\text {peak }}=k_{p}\left(2 q_{\infty} S_{p}\right)$

Reconstructed $k_{p}: 0.77$ (pre-flight range: $0.76-0.98$ )

- $\quad$ Force trace shows oscillations of roughly $20 \mathrm{~Hz}$ frequency (close to the parachute system frequency)

\section{SR01 was successful.}

- Validated Parachute test approach

- Met all test objectives.

- Yielded imagery and loads
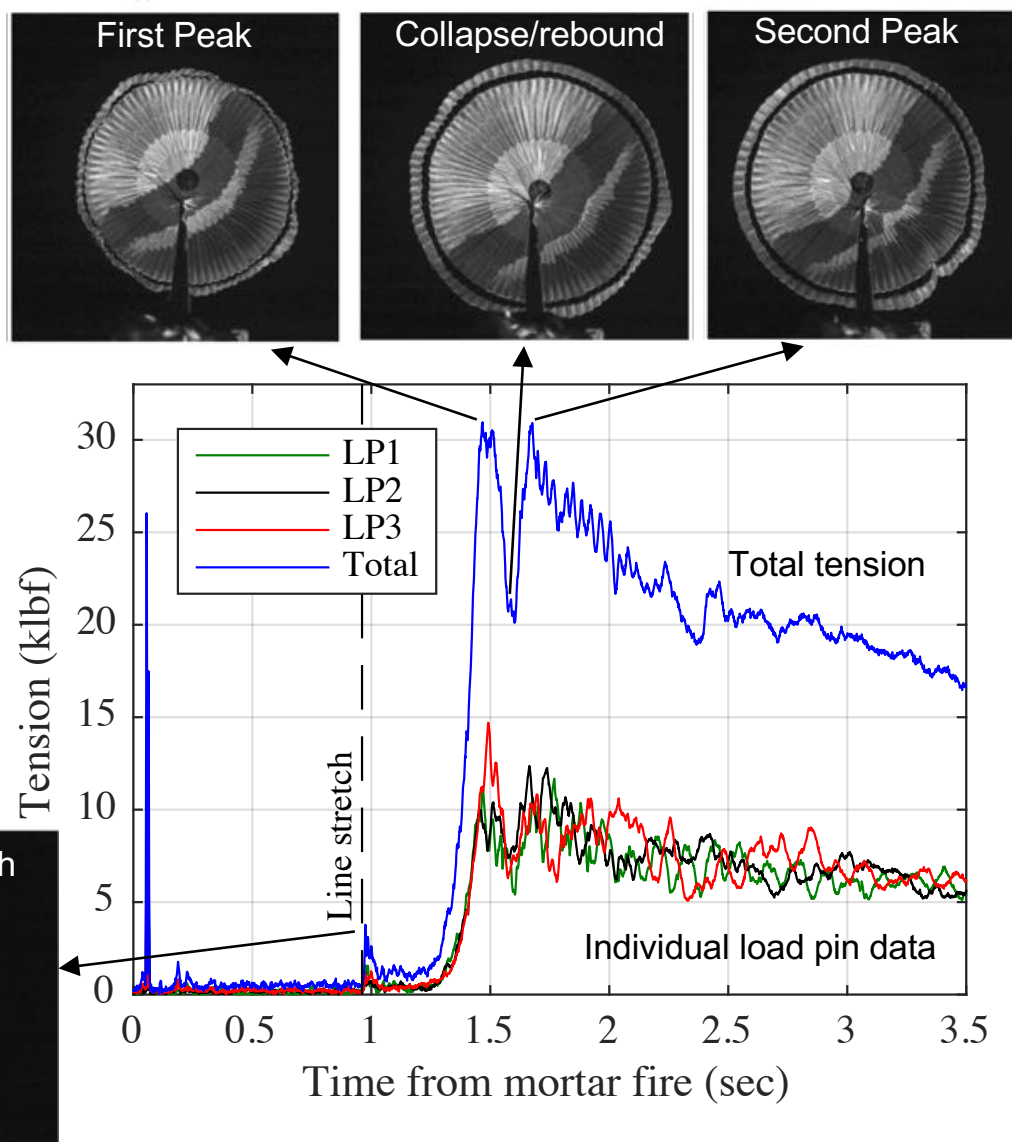


\section{Parachute Drag Performance}
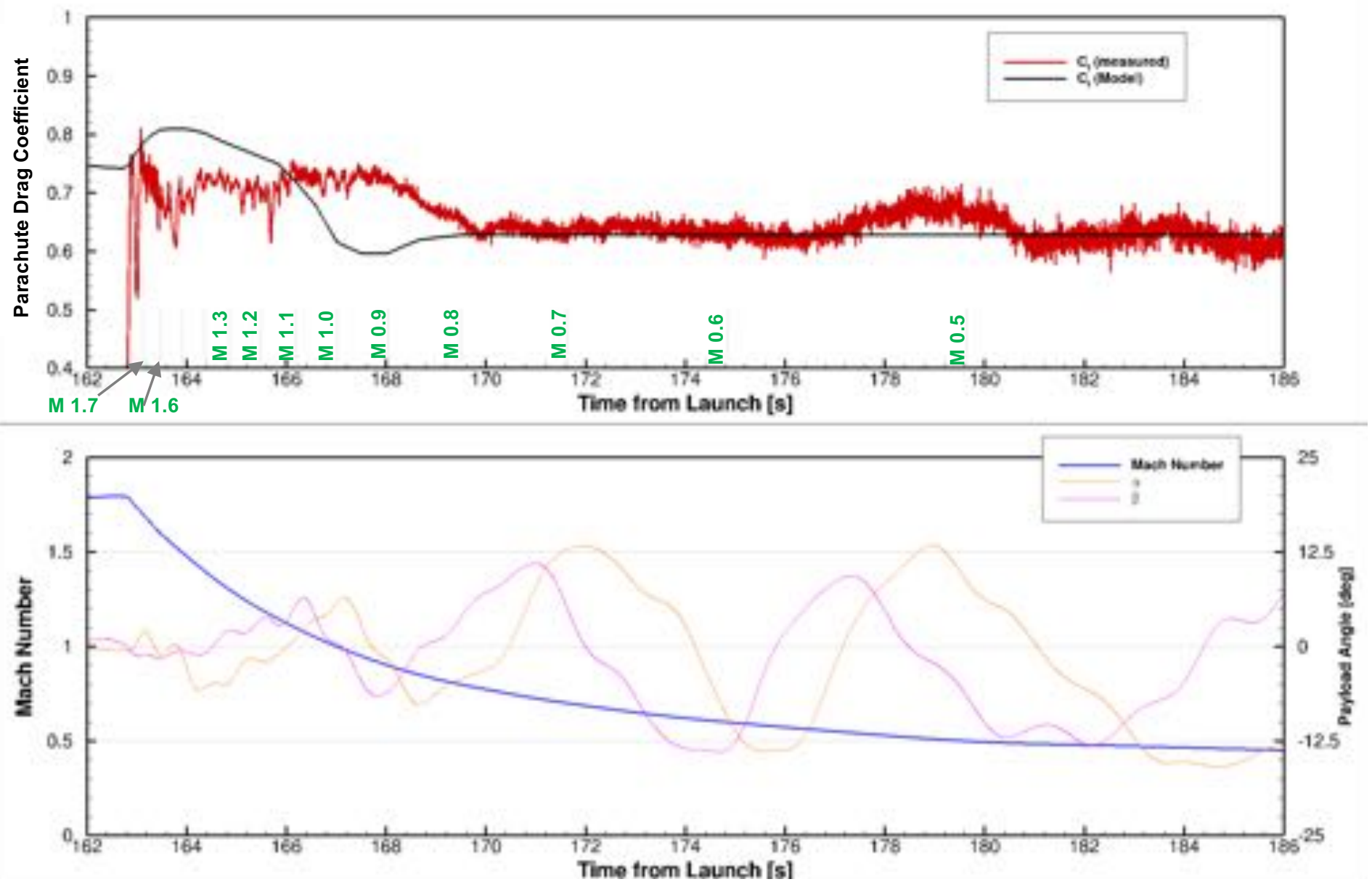

- Good agreement between modeled and measured drag (coefficient) below M 0.75; over-prediction above 1.15 (Vehicle attitude and parachute pull vector fairly small during this period)

- Test data does not exhibit a transonic reduction in drag (ongoing work: Is the transonic drag reduction related to the leading body geometry?) 


\section{Parachute Drag Performance}

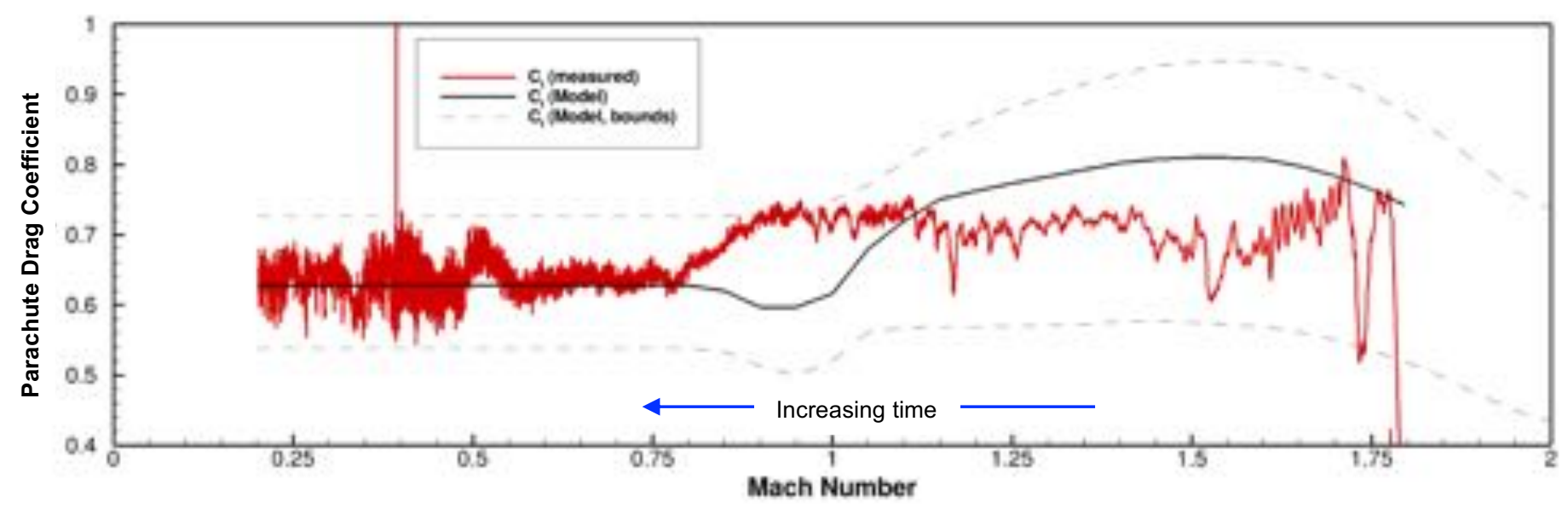

- Image shows test data against pre-flight model along with the (upper and lower) bounds

- Except for a brief instant near Mach 0.85 , the entire test data (roughly $30 \mathrm{~min}$ ) is well within the bounds

- Pre-flight model, bounds, used in flight mechanics simulations (next presentation) are reasonable

- This was the first of several ASPIRE flight tests planned; flight test data did not justify need to change parachute drag model for the second flight test.

- Parachute drag performance during SR02 (March 2018) was very similar to SR01. 


\section{Conclusions}

- $\quad$ ASPIRE project is testing supersonic parachutes at Mars relevant conditions

- $\quad$ Numerical simulations helped generate models for parachute inflation, deployment and loads (which in turn were used to target the flight test).

- $\quad$ First flight test (SR01) took place on $4^{\text {th }}$ October 2017

- $\quad$ The parachute was successfully deployed at the target conditions; force data and imagery were obtained.

- Mach Number 1.77

- Altitude $42 \mathrm{~km}$

- $\quad$ Pre-flight parachute drag model compares well to the flight test measurements.

- Supersonic parachute drag was over-predicted by about $10 \%$

- Test data does not exhibit transonic drag reduction

- Subsonic parachute drag was well-predicted

- $\quad$ Second flight test (SR02) took place in March 2018

- $\quad$ Third flight test (SR03) is scheduled for July 2018

- Ongoing analysis

- 3D parachute shape reconstruction from stereo videogrammetry

- Investigation of supersonic drag: CFD simulations at flight-like conditions \& geometry

- Static aerodynamic coefficients \& parachute/payload dynamics 